\title{
Why - Living in a War Zone?
}

\author{
Nancy Bauser* \\ NSB Group, Bloomfield Hills, Michigan, USA
}

\begin{abstract}
ISSN: $2455-5487$ DOI: https://dx.doi.org/10.17352/jnppr
Received: 16 March, 2020

Accepted: 09 September, 2020

Published: 10 September, 2020

*Corresponding author: Nancy Bauser, NSB Group, Bloomfield Hills, Michigan, USA,

E-mail: nancy@survivoracceptance.com

https://www.peertechz.com
\end{abstract}

Check for updates

After a trauma, an illness, a disability or an addiction, life becomes an uphill battle in all situations. Whether it is dealing with doctors, drug companies, mental health or rehabilitation professionals, living as an independent, self-sufficient human being is simply no longer possible. There are countless adjustments, accommodations and modifications that must be made, in order to ensure a quality life will be realized.

Now, let us bust some myths about living with challenges. First, true independence is no longer possible. Total dependence on anything is undesirable. A mixture of both, independence or self-sufficiency and dependence or getting assistance when needed, becomes your new normal. Being interdependent with the environment becomes your new success strategy. Not over-using available support shows strength, as progress and goals are achieved.

It is important to remember that behavior after tragedy is often fleeting. Needing reminders of directions is not unusual or a cause for concern. Having memory problems is simply part of your new way of being. When life as you had known it ends, you must fight your way back! That is the absolute truth - for everyone. Regardless of the injury, disability, illness or addiction, that is just the way it is.

With any wound, it takes time to recover. Circumstances never seem to get back to just the way they were. When the realization smacks you, that you cannot do things the way you used to, then a choice needs to be made by you. Do you give up and stop trying or do you fight the long battle back? It is your choice. No one can decide for you, not your significant other, your parent, employer, doctor or commanding officer. They can help you on your journey back to health and well-being, but they cannot do what needs to be done. Only you can! So, what do you do?

Those of us who have suffered any kind of trauma all know what hell is like for us. Since hell is hell for everybody, we are talking about the same place. We have all been there at some time on our recovery journey. Getting out of hell is simple, but it is not easy or quick. In fact, it is very gradual. Some days or hours are better than others. You can have a good day, one day and the next is bad. One day you are able and the next you are not. What do you do? I can tell you what I do, and then you can decide what it is that you want to do.

Having had a severe closed head - brain stem injury in 1971, I have had more than my share of medical and psychological problems. I address my difficulties as they arise. I see lots of specialists and I undergo different medical procedures, all the time. I do not complain. That is just how I live.

I am as healthy as I can be for a wounded person. I have problems with my balance, my memory \& the organization of my days. I must write down everything that I want to do and remember. I take public transportation. I do not work at a mainstream job and I cannot predict which days I will be able to act the way I want to and which days are ones that I won't have the stamina to perform effectively. Oh well - that is my life in a nutshell.

Becoming a person who produces desired results is about recognizing and building character strengths. We owe it to ourselves to examine our own lives and decide who it is we really are, what our conduct should be and how we wish to live the rest of our lives. It takes time and preparation to genuinely commit to acting on long standing problems. Only after acknowledging and then admitting, that I have difficulties can any plans for action have a chance of long-standing success.

When a person recognizes that they have a problem and seriously begins to consider solving it, they move from being a victim of their own circumstances, to an active participant in determining their future. A modicum of awareness precedes taking action to solve problems. The degree of difficulty encountered depends on what needs to be fixed. When someone is sincerely committed to change, then capitalizing on strengths and managing weaknesses, becomes the most direct route to accomplishing goals. 
Making a solid commitment to building character strengths is a cornerstone for taking effective action and building a new life. In order to improve performance, persistence is required. The key to living a good life is finding out what you want to do and then, attempting to do it. It is that simple, but not always easy.

Suppose you were to ask me; After having suffered a trauma, how do I live as well as I do? I would say that I knew acceptance was the key to living a good life. At all times I must take three necessary steps. First, I acknowledge that I have a problem. Then, I admit that fact to myself. After taking those two difficult actions, I need to accept reality or where I am at that specific time. These behaviors will allow me to take small achievable steps to improve some aspect of how I am seen by other people.

Constantly and continuously learning new information and acquiring new skills is some- thing that also must be done. Though it takes me longer than others to complete tasks, I simply refuse to give up, no matter how long it takes me to reach my goals. In order to regain control over my life and my future I had to believe that I was a new person. Though like my pre-injury self, some important things were different. I had limitations which required goals founded in my new reality.

I was only able to accept my new self a little at a time. Immediately after my trauma, denial dominated my life. Repeated failure eroded this denial. Improvement was not possible until I experienced fully what I had lost. When I was done grieving for each lost ability, I eventually became ready to accept the loss and carry on with my recovery. My recovery required persistence through the most devastating defeats that I could imagine.

Everything I have accomplished means absolutely nothing, if I cannot overcome the obstacle that seems insurmountable at that time. I have learned that with time, persistence and attention to physical, emotional and intellectual limitations, I can conquer that which is difficult! Always attempting to make a new start and failing repeatedly would lead to my inevitable collapse. Because of my many defeats, some people expect less of me. I can do nothing about that! I only worry about myself and what I do.

I am pleased to say that my story has taken a happier turn. Over thirty-one years ago, I married my best friend and began to pay better attention to my limitations. Many of the lessons I learned after my trauma, I wrote about in my book, Acceptance Groups for Survivors, A Guide for Facilitators. The primary purpose of this work is to demonstrate to readers, that they can say to clients, or if clients or survivors are the readers, they can say to themselves:

You are fine just the way you are. You define what recovery means for you and you determine your own timetable for achieving goals. Recovery is not only making progress it is taking one step.

Since acceptance is fluid and not something you achieve and retain, having an attitude of acceptance in one situation does not necessarily carry over to the next. When you recognize that acceptance is not something that is fixed, then you can understand why I created a support group format that covers 24 subject areas. The group is divided into four, six-week sessions. At the beginning of each meeting are the objectives for that session. Each group stands on its own, therefore it is not necessary that everyone start at the same time or attend every group. The Acceptance Group's opening statement is:

"Recovery does not mean that you wake up one day and you're fine. It does not mean that you do not get confused, and it certainly does not mean you regain the life you had prior to the injury, disability or illness.

Recovery to a person with an injury, disability or illness is making progress. Making progress is ACCEPTING your deficits, learning success strategies to help you with those deficits and learning to love and value yourself".

Nearly five decades have passed since I sustained my injury. I have made a lot of progress and I still ask myself, Is It All Worth the Struggle? I believe it is not a sign of illness or insanity to question my own existence in times of distress. It is just my way of coping. Thinking about and acting on are two hugely different activities. I can consider anything and not harm myself or others. I can choose to act, only in my own best interests.

Have you ever wondered how you would feel if you woke up and did not know why you were, wherever you were? I am not talking about waking up after over-indulging in some substance or forgetting where you slept. I am asking if you have ever been betrayed by your memories? Suddenly, you are unable to do what you remember you could do. Your life terrifies you. You trust no one and you cannot remember needing the assistance that you now require.

What do you do? How can you survive? Why is changing your thoughts and behaviors so difficult, yet so absolutely necessary as life continues to evolve. How do you react when a new obstacle, one that was previously denied, not recognized or ignored, presents itself with all the others that you are trying to manage?

My closed head - brain stem injury or my trauma, is a reality in my life. If I want to live as well as I can, be free from pain, not have seizures or depression and be able to sleep through the night, I follow my many doctors' orders. That sounds simple, but unfortunately, it is not always easy. I wish things were different, but they are not. All I can do is the best that I can, and like myself in the process. I have lived with my neurological deficits for over 50 years. Like all my other challenges, I need to have a strategy for what comes next. In order to win the war against my difficulties, I need a battle plan. Mine is:

\section{1) It is best to confront rather than avoid my problems!}

2) I think of myself as a warrior, fighting against the parts of myself that I do not like, or the deficits created by my injury, disability or illness. 
3) As long as I remain ignorant of my problems and unaware of the effect that I have on others, I will be unable to avoid or reduce my own suffering. When I familiarize myself with the difficulties that might occur, my distress seems to be reduced as well as my fear and anxiety about life with all my problems. When I no longer need to be afraid of what might happen, I can better prepare myself for the options or Success Strategies that I must make.

4) I set goals that are realistic and attainable. I recognize my difficulties in the here and now. When bringing about genuine change, I make a sustained effort. While it is important to set reasonable expectations and respect the reality of my situation, it is also important to never lose sight of what I eventually hope to achieve.

I constantly repeat to myself; Recovery is Making Progress! It does not matter where I start; doing anything to make my life better, is making progress!

Winning the battle to be fit is simple, but not always easy. You either do it or you don't - that is the simple part. Living as physically well as possible, is a choice that everyone makes for themselves.

Doing what you need to do in order to achieve your personal health goals takes a lot of work. Sometimes that seems easy and fun. More often, it feels like a chore that you want to avoid. However, maintaining the commitment to regularly exercise is critical. According to a lifestyle trainer and coach, being "fit" is relative to each person it applies to. This trainer goes on to say, "In general, I would define being fit as being able to perform your daily duties without the risk of injury. It could be something as routine as grabbing a case of water bottles from the bottom of a shopping cart or shoveling snow. To be "fit" is very different for each individual".

Everyone starts their quest for fitness somewhere. One person's goal may be as simple as getting out of bed in the morning. Another person's goal may be walking or lifting weights for 30 minutes. Whatever it is, the most important thing is that you do something about it. This means exercising, both mentally and physically. Without mental discipline, a person will probably not commit to a fitness program long enough to see results. Without physical exercise, forcing your body to adapt, become stronger and surpass fitness goals will most likely not be done.

People are often traumatized when they witness somebody getting killed, being hurt or are wounded themselves. Suddenly death is real. War results in pain, anguish and suffering for all involved. War is hell! Nobody goes untouched. It is time to break the silence and admit reality.

The reality is that all warriors return from the battlefield of life with emotional scars of some kind. The chaos and ferocity of combat, combined with fear and anger causes a soldier or person, to do things they would never do in regular circumstances. It is hard to go from battle-ready to civilian life, or from kicking in doors and firing weapons, to listening to someone complain about the traffic or not remembering a casual meeting with a friend, or appointment with a doctor or therapist. When you are in a war zone, you must be highly focused and alert to every detail.

You scan, analyze and prepare. When you are out in public, you spend a lot of time and energy deciphering information that you are taking in. You are hyper-vigilant, and this takes a lot of energy that most people do not have to use. The pressure to not make any mistakes is enormous.

Sadness and emotional pain are natural human emotions and crying is one-way people are wired to express grief. It is a healthy thing to verbalize emotions and release unhappiness. It is cathartic and necessary. It is like lancing a boil to get all the bad stuff out. Unresolved grief may be coming to the surface, when you find yourself having difficulty adjusting to life at home or at work. It can no longer be ignored or denied. When something tragic happens, life changes forever.

Now, you know what it is like to lose a brother or a sister, a comrade in arms, a part of your body or the ability to move or function in a known way. Perhaps, you have lost a job and your reason to get up in the morning. Loss is no longer foreign to you. You live with it every day, in all situations. Many veterans and those who remain alive after a catastrophic event, blame themselves even if there was nothing they could have done to prevent the injury, disability, illness or trauma. No one can control the uncontrollable and it is unacceptable that we cannot prevent tragedy from happening.

Mental health professionals will tell you that there are stages people typically go through when dealing with grief. First is denial. "This cannot be true!" Once reality sets in anger \& outrage tend to follow. On the heels of these feelings, sadness frequently sets in. Scattered among these very intense feelings is another stage of grief management and that stage is bargaining.

Nobody knows how they are going to react in a crisis. You do your best to psychologically prepare yourself, but sometimes biology just wins. Self-preservation is a basic human instinct. That is why people need not feel guilty when they freeze up in a combat or a potentially dangerous situation. The definition of bravery or courage is being afraid but doing it anyway. Fear is not only a natural reaction to danger it is a survival instinct. It is the mind's way of letting you know that something is wrong.

Survival is a strong driving force for all living things. It is important to be aware of and show respect for, the person or people involved in a crisis, even if it was yourself. Frequently in war, the mind is programmed to override natural survival instincts. That is why the military has its combat forces train, train and train again.

Behavior must be so automatic that it takes precedent over rational thinking. One of the hardest things for anyone to understand is why the trauma happened. Our human brains demand a logical explanation. It is unfortunate that lifethreatening situations often have no acceptable explanation. Life is just not fair! 
It is not uncommon for people to have nightmares after they have experienced horrific circumstances. Dreams and nightmares can be the mind's way of working through a crisis. The subconscious mind takes over and tries to take care of business. In other words, it attempts to fix the problem. For example, because the mind finds that it cannot accept that you have been in a catastrophic or near fatal accident, your brain searches while you're asleep for a way to make the situation have a good ending or positive outcome.

Sadly, in the real world, there are countless "no-win" situations. When life-threatening events have taken place, the mind finds it incomprehensible that such a tragedy could occur. The subconscious mind simply refuses to accept that something so horrific and catastrophic could take place. It is understandable that trauma has a profound effect on a person's beliefs and spirituality.

Catastrophe or near-death experiences impact a person's beliefs about the existence of God or a higher power. Most people believe that they will live a long and healthy life. After surviving a trauma, the knowledge that you are not guaranteed anything is real. Injury, disability, illness and death are no longer abstract concepts. You realize that you are not as invincible as you once believed.
Whether the problem stems from a conflict or trauma, an accident, an injury, illness or job loss, the devastating effects on individuals and their families is the same. Suddenly, you know that devastation is a real possibility. Your beliefs about the world, along with your values and morals, are all affected by the calamity you have lived through.

People who have survived a trauma and combat veterans have a lot in common. Both need to push beyond their limitations. As we grow older, we begin to realize that our internal resources are a limited commodity. Hopefully, we have learned to recognize that we must work smarter, not harder and it is in our best interests to be proactive in allocating our resources. We now must pay closer attention to our priorities and how we spend our energy.

The course of the healing process varies for everybody and there can be no set time for resolution. Everyone recovers from the effects of injury, illness, disability, crisis or war at their own pace. The recovery process has lots of ups and downs, particularly in the beginning.

It can be like a roller-coaster, but do not give up. Finding even ground is possible. It just takes a long time and a lot of hard work!
Discover a bigger Impact and Visibility of your article publication with

Peertechz Publications

Highlights

* Signatory publisher of ORCID

* Signatory Publisher of DORA (San Francisco Declaration on Research Assessment)

* Articles archived in worlds' renowned service providers such as Portico, CNKI, AGRIS, TDNet, Base (Bielefeld University Library), CrossRef, Scilit, J-Gate etc.

* Journals indexed in ICMJE, SHERPA/ROMEO, Google Scholar etc.

* OAI-PMH (Open Archives Initiative Protocol for Metadata Harvesting)

* Dedicated Editorial Board for every journal

* Accurate and rapid peer-review process

* Increased citations of published articles through promotions

* Reduced timeline for article publication

Submit your articles and experience a new surge in publication services (https://www.peertechz.com/submission).

Peertechz journals wishes everlasting success in your every endeavours.

Copyright: (c) 2020 Bauser N. This is an open-access article distributed under the terms of the Creative Commons Attribution License, which permits unrestricted use, distribution, and reproduction in any medium, provided the original author and source are credited. 